\title{
Vaccine responses in newborns
}

\author{
Anja Saso ${ }^{1}$ - Beate Kampmann ${ }^{1,2}$
}

Received: 1 July 2017 / Accepted: 18 September 2017 / Published online: 9 November 2017

(C) The Author(s) 2017. This article is an open access publication

\begin{abstract}
Immunisation of the newborn represents a key global strategy in overcoming morbidity and mortality due to infection in early life. Potential limitations, however, include poor immunogenicity, safety concerns and the development of tolerogenicity or hypo-responsiveness to either the same antigen and/or concomitant antigens administered at birth or in the subsequent months. Furthermore, the neonatal immunological milieu is polarised towards Th2-type immunity with dampening of Th1-type responses and impaired humoral immunity, resulting in qualitatively and quantitatively poorer antibody responses compared to older infants. Innate immunity also shows functional deficiency in antigenpresenting cells: the expression and signalling of Toll-like receptors undergo maturational changes associated with distinct functional responses. Nevertheless, the effectiveness of BCG, hepatitis B and oral polio vaccines, the only immunisations currently in use in the neonatal period, is proof of concept that vaccines can be successfully administered to the newborn via different routes of delivery to induce a range of protective mechanisms for three different diseases. In this review paper, we discuss the rationale for and challenges to neonatal immunisation, summarising progress made in the field, including lessons learnt from newborn vaccines in the
\end{abstract}

This article is a contribution to the special issue on Immunocompetence of the Newborn - Guest Editors: Arnaud Marchant and Tobias Kollmann

Beate Kampmann

b.kampmann@imperial.ac.uk

1 Centre of International Child Health, Department of Paediatrics, Imperial College London, W2 1NY, London, UK

2 Vaccines and Immunity Theme, MRC Unit The Gambia, Fajara, The Gambia pipeline. Furthermore, we explore important maternal, infant and environmental co-factors that may impede the success of current and future neonatal immunisation strategies. A variety of approaches have been proposed to overcome the inherent regulatory constraints of the newborn innate and adaptive immune system, including alternative routes of delivery, novel vaccine configurations, improved innate receptor agonists and optimised antigen-adjuvant combinations. Crucially, a dual strategy may be employed whereby immunisation at birth is used to prime the immune system in order to improve immunogenicity to subsequent homologous or heterologous boosters in later infancy. Similarly, potent non-specific immunomodulatory effects may be elicited when challenged with unrelated antigens, with the potential to reduce the overall risk of infection and allergic disease in early life.

Keywords Neonate $\cdot$ Vaccination $\cdot$ Immune system $\cdot$ Infant . Immunisation $\cdot$ Immunity

\section{Introduction}

The World Health Organisation (WHO) estimates that $45 \%$ of deaths among children under the age of 5 years occur during the newborn period [1]. More specifically, neonatal infections currently account for $\sim 700,000$ of these deaths and $\sim 7$ million cases per year, with the greatest proportion affected and most severe outcomes in poorly resourced areas [2]. The burden of disease is high at this early stage due to the unique nature of the neonatal immune system specifically adapted to postnatal life, but simultaneously susceptible to infection and suboptimal vaccine responses. The transition from the sheltered inutero environment to the 'outside world', the lack of defence from vaccine-induced antibody and the profile of early pathogenic organisms all contribute to the newborn's vulnerability 
to microbial and environmental insults. Despite the limited ability of the neonatal immune system to develop potent memory responses, the success of the three vaccines administered in the immediate neonatal period, Bacillus Calmette-Guérin (BCG), hepatitis B vaccine (HBV) and oral polio vaccine (OPV), confirms that newborn vaccination can be effective at preventing three quite different diseases [3]. Furthermore, recent technological advances have enabled in vitro and in vivo modelling of early immune ontogeny with detailed characterisation of mechanistic processes. Along with the introduction of several significant global policy and funding initiatives to promote newborn and infant health, this has resulted in renewed interest in neonatal immunisation as an important tool to reduce the unacceptably high figure of neonatal mortality [4].

\section{The rationale for newborn vaccination}

Neonatal immunisation would provide early protection for newborns and infants, narrowing the critical period of vulnerability intrinsic to routine vaccination schedules that start later in life. Other immunological advantages have also been hypothesised: fewer vaccine doses may be required if an immunogenic response is elicited at this early stage; there may be a general immunomodulatory effect, boosting immunity from birth before exposure to viral or bacterial pathogens $[3,5,6]$. Equally, neonatal vaccination is easily implementable, given that birth is a crucial point of contact with healthcare systems globally; as such, effective newborn vaccines would achieve high population penetration, particularly important in poorly resourced areas with otherwise limited health care services [6].

\section{The ideal neonatal vaccine}

Important concepts for the successful development and impact of a neonatal vaccine include safety, immunogenicity and efficacy in addition to the establishment of a balance between reactogenicity/autoimmunity and immune tolerance [7, 8]. Ideally, a vaccine would be administered at birth (or before 4 weeks of age), via the oral rather than the intramuscular or subcutaneous routes, safely eliciting a strongly protective response after a single dose with minimal interference from maternal antibodies [3]. This response would be sustained or easily boosted as part of the subsequent routine infant immunisation schedule, without developing hyporesponsiveness when challenged with the same or concomitant vaccine antigens.

In this review article, we will discuss key features of the three vaccines currently recommended for use at birth. Furthermore, we will assess the main maternal, infant and environmental factors that may affect and/or hinder the success of future neonatal vaccines. Finally, we will summarise new strategies in the pipeline and remaining challenges to be addressed in the future.

\section{Systemic challenges to the use of vaccines in the neonatal period}

\section{Immunogenicity}

The main challenge to successful immunisation of newborns is achieving sufficient immunogenicity in the context of developing innate and adaptive immunity, primarily due to the distinct nature of neonatal leukocytes $[2,9,10]$. Crucially, the neonatal immunological milieu is skewed towards Th2-type immune responses, with dampening of Th1-type immunity and inflammasome pathways [4, 11-13]. These adaptations prevent alloimmune reactions between the mother and fetus, enable microbial colonisation and avoid excess proinflammatory responses $[6,10,14]$. Conversely, they render the newborn susceptible to infection and limit optimal vaccine responses $[15,16]$.

Neonatal CD4+ T cells are primarily recent thymic emigrants shown to have reduced immune function [17, 18]. Preferential CD4 T cell differentiation into Th2 effectors is thought to be partly mediated by epigenetic processes, specifically hypermethylation of IFN $\gamma$ locus and hypomethylation of the Th2 locus [19]. This is further enhanced by the reduced capacity of antigen-presenting cells (APCs) to produce Th2polarising cytokines, notably IL12 [2, 20]. Th1 cells also express IL4R $\alpha /$ IL $13 R \alpha$ heteromeric receptors, with high risk of subsequent apoptosis on ligation with IL4, a product of Th2 cells [21]. Moreover, there is a qualitative and quantitative increase in suppressive $\mathrm{T}$ regulatory cells which secrete high concentrations of IL10 and TGF $\beta$, promoting tolerogenicity of APCs and limiting effector T cell responses [5, 22, 23].

In addition to these classic Th1/Th2 responses, Th17 proinflammatory responses might also contribute to an important component of vaccine-induced memory [2]. Production of Th17 cell promoting cytokines IL6 and IL23 dominates in term infants [24].

Humoral immunity in neonates is impaired with a subsequent need for repeated vaccine doses; lower antibody titres are secreted with a narrower antibody repertoire and suboptimal functional responses to some antigens when compared to older infants [3, 10,25]. This reflects defects in neonatal B cell differentiation, with dominance of memory $\mathrm{B}$ cells versus plasma cells (PC), resulting in limited extrafollicular (EF) and germinal cell (GC)-derived plasma cell responses. This can be explained by both B cell-intrinsic and B cell-extrinsic factors: the former includes weaker B cell receptor-mediated signalling in naive $\mathrm{B}$ cells, the lower expression of costimulatory molecules for $\mathrm{T}$ cells and the slow maturation of marginal zone B cells that recognise pathogen-associated 
molecular patterns (PAMPs) with subsequently reduced Tindependent responses [25]. A key B cell extrinsic factor is the limited help provided by follicular dendritic cells (FDC) and/or $\mathrm{T}$ follicular helper (TFH) cells (the latter is mediated by IL12 which is reduced), thereby delaying GC induction [26-28]; dendritic cell activation signals and survival factors, such as A Proliferation Inducing Ligand (APRIL), are also suppressed [2, 27, 29]. On the other hand, high concentrations of adenosine in neonatal plasma selectively inhibit production of Th1-polarising cytokines via intracellular mechanisms, including induction of cyclic adenosine monophosphate (cAMP) [30, 31].

Given the limited exposure to antigens in utero, neonates are particularly dependent on their innate immunity to prime adaptive immune responses [32]. The unique characteristics of the newborn's innate immunity are therefore critical in explaining why they have suboptimal vaccine responses in comparison to older infants [5,33]. Above all, the functional activity of neonatal APCs is impaired, primarily because they express pattern recognition receptors (PRR), such as Toll-like receptors (TLRs), with distinct functional responses including limited antiviral and Th1-polarising cytokine production to most stimuli $[2,34,35]$. This cytokine ontogeny is thought to be due to epigenetic changes as well as differences in activity of interferon response factor (IRF) transcription factors. For example, there is impaired nuclear translocation of IRF7 thereby inhibiting transcription of IFN $\alpha$ and IFN $\beta$; reduced IRF3 DNA binding activity and association with the coactivator CRB-binding protein (CBP) also lead to lower type $1 \mathrm{IFN}$ production [24]. However, the precise molecular mechanisms underlying TLR-mediated innate function in early life have not been fully delineated and require further attention, since their potentiation would help to induce Th1 and TFH cell responses, thereby overcoming newborn adaptive immune deficiencies [5].

\section{All vaccines are not equal}

The impact of immunisation on this unique neonatal immune regulation milieu may vary between vaccine types. Infants immunised at birth with HBV or OPV develop lower Th1 type responses than adults. However, such Th1 responses are associated with higher antibody responses than in adults receiving booster doses [36, 37]. By contrast, it is now well established that BCG induces potent mature Th1 responses in newborns [38].

Multiple studies have explored the variable capacity of different vaccines to induce appropriate $\mathrm{Th} 1$ responses at birth, identifying determining factors such as antigen dose, type of adjuvant and route of administration [11, 13, 15]. Above all, the ability of APCs to potentiate adaptive immune responses plays a crucial role [5].

\section{Immune interference and hypo-responsiveness}

There is theoretical concern that neonatal vaccination may result in the subsequent development of immune hypo-responsiveness, particularly when challenged with either the same antigen ('immune paralysis/tolerance') and/or concomitant antigens ('vaccine interference') in subsequent infant immunisation schedules [3, 6, 39].

Halasa et al. demonstrated that the administration of an additional dose of diphtheria, tetanus, acellular pertussis (DTaP) at birth was safe but also associated with significantly reduced antibody response to three of the four pertussis antigens (pertussis toxin and pertactin at 6,7 and 18 months and fimbrae at 6, 7, 17 and 18 months) and to diphtheria antigens at 7 months when compared with controls. Immune responses to all other vaccine antigens were comparable including HBV and tetanus toxoid [40].

By contrast, Knuf et al. showed that priming at birth with a three-component standalone aP vaccine was well tolerated and resulted in significantly higher antibody responses to the three pertussis antigens at 3 months of age (after the first dose of $\mathrm{DTaP}$ vaccine had been given) in comparison to controls. Early neonatal immunisation with aP did not elicit immunologic tolerance to pertussis antigens, with all subjects reaching antibody concentrations above the protective threshold 1 month after completing the vaccine course, although it did dampen responses to Haemophilus influenza $B$ (Hib) and HBV vaccines [41]. Given that the maternal antibody levels in newborns were comparable in both studies, their contrasting results were thought to be secondary to the different vaccine formulations and/or adjuvants used or to the additional birth dose of HBV given in the former trial. Furthermore, Knuf et al. have proposed that the robust secondary $T$ cell pertussis-specific responses, induced after the first DtaP-IPV-HBV/Hib vaccine dose, may have subsequently interfered with adequate recruitment of $\mathrm{CD} 4+\mathrm{T}$ cells needed to activate a strong primary response to concomitantly administered $\mathrm{HiB}$ and $\mathrm{HBV}$ antigens, known as 'bystander interference' [41, 42].

Other studies using different vaccines have disputed this concept of immune downregulation. As part of the large randomised, multi-centre clinical trial of BCG given at birth, the Danish Calmette Study, Nissen et al. investigated the effect of BCG at birth on the antibody response to the three routine vaccines against DTaP-IPV-Hib and Prevenar 13 in a subgroup of participants. BCG did not reduce the probability of having antibody titres above the limit of protection with seroprotective levels detected for each of the three vaccinations in almost all children 4 weeks post vaccination. There was also no difference between BCG and controls with respect to geometric mean concentrations (GMC) of antibody even when adjusted for the background factors [43]. Similarly, no interference has been observed 
between OPV and the vaccines administered alongside it as part of the WHO routine immunisation schedule [44].

\section{What can we learn from vaccines currently administered to neonates?}

\section{Bacillus Calmette-Guérin}

BCG is a live attenuated Mycobacterium bovis vaccine administered within the first few days of life in most countries to prevent tuberculous (TB) meningitis and disseminated TB disease in children. It is the most widely used vaccine worldwide with an overall excellent safety record. Adverse reactions range from localised inflammation and scarring at the site of inoculation ( $95 \%$ of healthy neonates) to more serious, systemic events including axillary and cervical lymphadenopathy and, very rarely $(<1$ in million), disseminated BCG infection $[45,46]$.

As yet, no surrogate immune marker of BCG-induced protection has been identified [47]. Clinical markers of its efficacy are used instead. Crucially, there is $73 \%$ protective efficacy against TB meningitis and $77 \%$ against miliary TB [45]. However, there is no convincing protection against primary pulmonary infection or reactivation of latent TB, and protective efficacy declines to non-significant levels after 10-20 years [45, 48, 49]. Moreover, BCG efficacy is variable and may depend on several factors including the immune status of the recipient [50], prior exposure to environmental mycobacteria (both $M$. tuberculosis and nontuberculous mycobacteria) [51], strain variation in BCG preparations [52] although this has been contested [53], genetic or nutritional variability and environmental factors including sunlight exposure and poor cold-chain maintenance $[6,51]$. Prior exposure is thought to both limit replication of BCG and/or confer protection equivalent to BCG ('masking'). Given that this is dependent on age, it would explain why mycobacteria-naïve newborns appear to benefit more from BCG vaccination than older individuals [53].

BCG does not contain any exogenous adjuvant but is inherently 'self-adjuvanted' because Mycobacteria induce immune responses via TLR2, TLR4 and TLR8 [52]. BCG induces a potent Th1 polarised immune response to mycobacterial antigens, thereby overcoming the common obstacle faced by newborn vaccinations and confirming that reduced Th1 capacity in neonates is not absolute [54]. Studies among infants demonstrate BCG-associated induction of CD4+ and (to a lesser extent) CD8+ T cells, IFN $\gamma$, IL2, TNF $\alpha$ and polyfunctional CD4+ T cells [55]. However none of these responses were found to correlate with protection against TB in BCG-immunised infants [56].

Neonatal BCG vaccination may also have non-specific, heterologous beneficial effects, boosting the innate and adaptive immune responses to unrelated antigens and reducing morbidity and mortality from non-tuberculous infections as well as allergic diseases [57-62]. The nature and significance of such effects, however, remains controversial and it cannot be excluded that neonatal vaccination may have a similar masking effect on vaccines administered later in infancy, as already observed between early exposure to (environmental) mycobacteria and BCG [63-66].

Ota et al. demonstrated that BCG boosted cytokine and antibody responses to unrelated vaccine antigens (HBV and $\mathrm{OPV}$ ) in neonates, probably by influencing maturation of dendritic cells. The finding that both Th1 and Th2 cytokines increased suggests that the magnitude but not the quality of neonatal responses to vaccines was influenced by BCG [38]. Similarly, an Australian study found that BCG was associated with significantly higher response of several subclasses of the pneumococcus conjugate vaccine (PCV) routinely given during childhood [67].

Although the underlying immunological mechanisms have not been fully elucidated, two hypotheses have been proposed for these non-specific effects: 'trained innate immunity' and 'heterologous immunity'. 'Trained innate immunity' describes the ability of the innate system to generate immunological memory and therefore be 'trained' to provide partial protection against subsequent infections, independent of classical $\mathrm{T}$ and $\mathrm{B}$ cell adaptive immunity [68-70]. Natural killer (NK) cells and monocytes have emerged as central to trained immunity in mammals via functional reprogramming of PRR (e.g. NOD2 receptor) $[71,72]$. Primary exposure to microbial ligands alters the fate of monocytes, dependent on the nature and concentration of the ligand, mediated by epigenetic mechanisms at the level of H3K4 trimethylation [71].

The second immunomodulatory process proposed is 'heterologous immunity'. This describes the effects on the adaptive immune system, primarily T cell-mediated cross reactivity between vaccine-related and vaccine-unrelated antigens. As such, T cell vaccine responses may be impacted and modified by encounters with pathogens from previous infections $[71,73,74]$. Although the WHO recently recommended that the existing evidence was insufficient to prompt a revision of immunisation policy, further studies are required to characterise the magnitude, duration and mechanisms of the nonspecific effects of vaccines and, therefore, their potential implications for infant health $[65,66]$.

\section{Hepatitis B vaccine}

There is extensive evidence of the excellent safety and immunogenicity profile of hepatitis $B$ vaccines. Administration of $\mathrm{HBV}$, in some cases with hepatitis B immunoglobulin (HBIG), remains the most effective way of preventing the high risk of mother-to-infant transmission of HBV [6, 75-77], and it has 
been demonstrated that timely administration of the birth dose results in the highest vaccine effectiveness.

The current widely used r-HBsAg vaccines, available since 1986, are a viral subunit that has been transfected with a plasmid that contains the $S$ gene (codes for HBsAg) either as a single preparation or in combined form. Alum, a chemical compound containing aluminium salts, is added as adjuvant.

The vaccine is highly immunogenic and induces potent neutralising antibody following a series of at least three doses. Recommended vaccination schedules that include a birth dose will prevent most perinatally acquired infections and offer early protection from horizontal transmission.

Anti-HBs antibodies are a marker of immunity and a titre of anti-HBs antibodies to HBVsAg $\geq 10 \mathrm{IU} / \mathrm{L}$ indicates seroprotection if measured 1-3 months after completion of the primary immunisation series. In healthy infants, 30-40\% protection against HBV infection is achieved with one dose of the vaccine, $50-75 \%$ protection with two doses and $>90 \%$ with three doses [6].

Four intramuscular vaccine doses are recommended in susceptible infants over the first year of life in the UK (three in the USA). Side effects are generally mild including pain at the injection site $(3-29 \%)$, mild fever $>37.7{ }^{\circ} \mathrm{C}(1-6 \%)$, malaise, headache, arthralgia and myalgia [6]. HBV immunisation induces at least equivalent antibody responses in newborns and adults; this suggests that the capacity of the newborn to develop antibody responses depends on the nature of the immune stimulus [9, 36]. Moreover, the success of the HBV schedule confirms that vaccination at birth can elicit potent memory B cell responses that promote immunogenicity of subsequent vaccine booster doses, irrespective of primary antibody response [5, 44].

Long-term protection against HBV infection depends on the persistence of strong immunological memory and can vary between individuals. After primary immunisation with HBV vaccine, anti-HBs concentrations wane quite rapidly within the first year and more slowly thereafter. However, even if anti-HBs concentrations decline to below $10 \mathrm{IU} / \mathrm{L}$, immune memory continues to persist over a longer time period. Booster doses are not currently recommended for fully vaccinated, immunocompetent individuals.

Similar to the immune response to HBV infection, T cell dependence of the immune response to hepatitis B vaccination has been demonstrated, and it was shown that non-responding infants had a reduced capacity to adequately expand and differentiate TH cells.

The $\mathrm{T}$ cell responses elicited by HBV have been shown to vary between newborns and adults. A study by Ota et al. demonstrated lower interferon- $\gamma$ production (reflective of Th1 immunity) but higher Th2 memory responses in those vaccinated at birth when compared with adults [36].

\section{Oral polio vaccine}

Two types of polio vaccines are in use worldwide: intramuscular (or subcutaneous) inactivated polio vaccine (IPV) and orally administered, live attenuated polio vaccine (OPV). In polio-endemic countries and in areas at high risk for importation and subsequent spread, WHO also recommends an OPV dose at birth (called 'zero' dose), followed by the primary series of three OPV doses with at least one IPV dose [78]. OPV therefore remains the first mucosal vaccine received by most newborns in low- to middle-income countries. A trivalent OPV formulation (tOPV) was used worldwide until April 2016 when it was replaced with bivalent type 1 and type 3 OPV (bOPV) during a global synchronised switch. Withdrawal of type 2 OPV was required because type 2 wild polioviruses no longer circulate, and its continued use had been responsible for a disproportionate number of vaccineassociated paralytic polio (VAPP) and circulating vaccinederived polioviruses (cVDVP) cases [78]. There is no extrinsic adjuvant within the OPV formulation; instead, it contains single-stranded RNA which activates the innate immune system by stimulating TLR8 [79].

Halsey et al. comprehensively summarised a large dataset obtained from different countries, using serological assays where results were adjusted for estimated decline of maternal antibody, and viral excretion assays in stool [44]. Overall, the summary data demonstrate that when administering a dose of tOPV and DTP in the first week of life, 50-100\% of newborns will benefit by developing active intestinal infections and local immune responses, while $30-70 \%$ of neonates develop serum antibodies to one or more poliovirus types. The wide confidence intervals are explained by a number of factors such as persisting maternal antibody at time of vaccination, breastfeeding, varying intervals of administration after birth and a range of geographic settings. Based on these data, the authors recommended the use of tOPV at birth in high risk areas where poliomyelitis has not been controlled [44].

A subsequent Egyptian trial confirmed the immunogenicity of a monovalent type 1 OPV given at birth and its superiority over previous trivalent formulations. Fifty-five percent of newborns in the monovalent-vaccine group seroconverted 30 days after priming. Nearly half of infants with high maternal antibody titres still secreted antibodies against type 1 poliovirus. Following challenge with type $1 \mathrm{OPV}$ at 1 month of age, $75 \%$ of infants did not excrete type 1 IPV [80].

By contrast, a study in Belgium used OPV as a model of early immunisation to investigate the capacity of young infants to develop cellular immune responses. They showed that weak IFN $\gamma$ and cell-mediated responses (i.e. limited Th1 responses) to polio antigens were induced post neonatal OPV when compared to immune adults. However, the titre of neutralising antibodies was high, above the protective threshold, similar to previous studies [37]. 
In summary, the considerable experiences with existing vaccines have shown that newborns are in fact able to mount robust immune responses to neonatal vaccines, particularly to live attenuated vaccines, but that such responses are influenced by a number of co-factors, as discussed in later sections.

\section{What can we learn from vaccines that have been investigated for use in neonates but are not currently part of recommended regimens?}

\section{Pneumococcal vaccines (PCV)}

Two recent trials have demonstrated that the delivery of seven valent pneumococcal conjugate vaccine (PCV7) to neonates may be safe and immunogenic, with no evidence of hampering potential long-term protection or inducing immune tolerance. The first trial, undertaken in Kenya, randomised young infants to either receive seven-valent PCV at 6, 10 and 14 weeks (EPI group) or 0, 10 and 14 weeks (neonatal group). Serotype-specific serum IgG and avidity were measured at birth and $6,10,14,18,36$ and 37 weeks. Infants were then boosted with either seven-valent PCV or one fifth dose of pneumococcal polysaccharide vaccine at 36 weeks. Results demonstrated excellent safety with minimal adverse effects. At both 18 and 36 weeks, there was no significant difference in the proportion of IgG above the protective threshold against each serotype between infant groups. However, geometric mean concentrations (GMCs) were lower in the neonatal group for serotypes $4,9 \mathrm{~V}, 18 \mathrm{C}$ and $19 \mathrm{~F}$ at 18 weeks and for serotype 4 at 36 weeks. By contrast, avidity was significantly higher in the neonatal compared to the control group for serotypes $4,6 \mathrm{~B}$ and $19 \mathrm{~F}$ at 18 weeks and for serotype $19 \mathrm{~F}$ at 36 weeks likely because affinity maturation would have occurred for longer since birth. The clinical significance of these avidity findings is uncertain and it could be argued that lower GMC could lead to non-protective responses at an earlier stage. However, this did not occur during the follow-up period of 37 weeks. Response to the 36-week boosters and prevalence of vaccine-type/non vaccine-type carriage were comparable between groups, suggesting absence of immunological tolerance after neonatal vaccination [81, 82].

Similarly, Pomat et al. conducted an open randomised trial in Papua New Guinea to compare infants given PCV7 in a 01-2-month (neonatal) schedule with that of the routine 1-2-3month (infant) schedule. All infants received 23-valent pneumococcal polysaccharide vaccine (PPV) at age 9 months. By 2 months of age, GMCs for serotypes $4,9 \mathrm{~V}, 18 \mathrm{C}$ and $19 \mathrm{~F}$ were significantly higher in the neonatal than in the infant group, taking into account that the neonatal group had received two doses of PCV7 compared with the single dose in the infant schedule. Post-hoc analysis of the differences in proportions of children with protective antibody levels at age
2 months did not demonstrate superiority of two doses in the neonatal group over one dose in the infant group. While all antibody responses to vaccine types in the neonatal group were non-inferior to those in the infant group at age 2 months, over time the infant-immunised group generally had higher $\mathrm{Ab}$ levels than the neonatal-immunised group. On subsequent challenge with PPV at 9 months, significantly higher serotypespecific $\operatorname{IgG}$ concentrations above the protective threshold were induced in PCV7 primed compared to unprimed infants; neonatal and infant groups had equivalent antibody levels, which persisted until the end of follow-up at age 18 months. These results again suggest an absence of tolerance following neonatal PCV vaccination $[82,83]$.

\section{Pertussis vaccines}

Immunisation within $24 \mathrm{~h}$ of life with whole cell pertussis or combined with diphtheria and tetanus vaccines has previously demonstrated a good safety profile, with no moderate or major adverse effects documented [84]. Th1-type immunity was preferentially induced, in a similar way to BCG. However, the serological response was suboptimal and a reduced response to pertussis boosters was documented in $75 \%$ of study subjects until 5 months of age, independent of maternal antibody titre which was low. This can probably be attributed to antigen-specific immunological hypo-responsiveness, already discussed previously. By contrast, if immunisation was delayed to 3 weeks of age, the serological response was adequate $[85,86]$. Based on these findings, the WHO recommends starting pertussis immunisation schedules from 6 weeks of age.

Due to the recent resurgence of severe pertussis in early life, there has been renewed interest in administering aP vaccines at birth, either as a sole vaccine or as part of DTaP combined vaccine. The results of these studies have been conflicting, as discussed previously, with concerns regarding tolerogenicity both to the same antigen administered later in infancy or 'bystander interference' to concomitant antigens. $[40,41,87,88]$

\section{Vaccines against viral pathogens}

The high burden of respiratory and gastrointestinal disease in early life warrants the further study and development of neonatal vaccines against RSV, parainfluenza, influenza and rotaviruses, ideally administered via the oral or nasal route to induce effective mucosal immunity. Neonatal immunisation against RSV is currently under consideration with several vaccine candidates under development, but none has yet progressed to licencing [89].

A recent pilot study enrolling 66 infants into two equally sized groups comparing pentavalent rotavirus vaccine (RV5) administered on an early alternative dosing schedule (at 2- 
5 weeks of age) compared with RV5 administered on the current WHO standard schedule, measuring safety, serumneutralising antibody (SNA) and IgA geometric mean titers (GMTs). RV5 was found to be generally well tolerated and immunogenic in the neonatal period, although the rotavirus SNA serotype 4 response was less robust in newborns than in infants on the standard schedule [90].

\section{Co-factors affecting responses to newborn vaccines}

\section{Maternal infections and maternal antibody}

The maternal factors potentially affecting the success of neonatal immunisation are threefold: maternal-fetal transfer of antibodies, maternal-fetal transfer of pathogenic organisms and chronic maternal infections.

Maternal antibodies, transplacental or milk-derived, may potentially interfere with the neonatal adaptive immune response and subsequent vaccine responses [91, 92]. This has already been shown in the context of maternally derived antibodies inhibiting immunogenicity of the measles vaccine in infants [93]. The suppressive effect is thought to depend on the ratio between antibody titre and vaccine antigen dose, given that circulating antibodies hide the antigen from the host's immune cells thereby masking B cell epitopes [92]. This is exacerbated by the unique nature of the neonatal Fc receptor which increases the serum half-life of passively transferred antibodies [5, 94]. By contrast, other studies have shown that the infant's APC uptake and T cell responses appear to be largely unaffected by maternal antibody [13]. Further research is currently ongoing to gain better mechanistic insights. Antibodies in breast milk may similarly limit the efficacy of oral vaccines at the mucosal surface, although this has been contested [95-97]. A recent study by Ali et al. demonstrated that withholding breastfeeding around the time of rotavirus vaccine administration did not improve vaccine immunogenicity with no increase in anti-rotavirus IgA seroconversion measured [98].

Transmission of pathogens across the placenta to the infant can also play a role in early life immunity with a potential impact on newborn vaccine responses: HIV-associated immune compromise, particularly cellular immune deficiency, exacerbates poor neonatal vaccine outcomes and some adverse effects. In a study carried out in South Africa between 2004 and 2006, the pooled incidence of disseminated BCG was estimated to be as high as 992 per 100,000 HIV-infected vaccinees, almost 1000 times higher than those who were HIV-uninfected [99]. The mortality rate associated with disseminated BCG disease was > 70\% [99, 100]. Other pathogens that are vertically transmitted and may potentially affect neonatal immunity include toxoplasmosis, rubella, CMV and other herpes viruses, syphilis, enterovirus, parvovirus B19 and hepatitis viruses. A comprehensive discussion of the impact of each disease on vaccine responses is beyond the scope of this review.

Chronic maternal infections may shape neonatal vaccine responses by their impact on maternal antibody transfer across the placenta or their generalised effect on the developing neonatal immune system. This occurs independently of vertical transfer of pathogenic organisms and is secondary to exposure to microbial antigens, either free or complexed with immunoglobulins crossing the placenta. Subsequently, there is sensitisation in-utero and induction of adaptive, inflammatory and regulatory responses [101]. The unique maternal disease profile during pregnancy may contribute to the observed differences in immune responses of infants in developed compared to developing countries [102].

During pregnancy, prevalence of infection with at least one helminth species is $10-70 \%$ in endemic regions [101]. Detection of specific immunoglobulins, particularly IgE, to various helminth species in cord blood reflects in-utero sensitisation of both $\mathrm{B}$ and $\mathrm{T}$ lymphocytes to microbial antigens, while parasites are rarely transmitted vertically [103, 104]. Poor T cell responses to tetanus toxoid (TT) immunisation and reduced $\mathrm{HiB}$ vaccine-specific antibody responses have been reported in neonates born to mothers with lymphatic filariasis and/or schistosomiasis [105]. Furthermore, Malhotra et al. found that Kenyan infants born to mothers infected with Schistosoma haematobium and sensitised in utero had lower IFN $\gamma$ responses to BCG than did unexposed infants [106]. A similar pattern was seen in the context of maternal filariasis during pregnancy [106]. By contrast, Elliot et al. concluded that maternal helminth infection may have little, if any, adverse effects on the outcome of infant immunisation. Of note, only maternal Mansonella perstans infection was associated with significantly higher IL10 responses to BCG and tetanus immunisation but with no reduction in IFN $\gamma$, IL5 and IL13 responses [107].

Maternal infection with Trypanosoma cruzi and congenital Chagas disease induces a trend to type 1 polarisation of infant immune responses to vaccines. High levels of IFN $\gamma$ were noted in response to BCG administered in exposed but uninfected infants compared with congenitally infected infants or unexposed and uninfected infants [108].

Data on vaccine responses of HIV exposed but uninfected newborns are conflicting. On one hand, studies have found that their humoral and cell-mediated responses to vaccines, including to the measles vaccine and BCG, are similar to responses in unexposed infants [109, 110]. Moreover, Jones et al. demonstrated that HIV exposed uninfected infants born in South Africa mounted higher increments of antibody responses to pertussis and pneumococcus vaccines [111]. This may be because the reduced transfer of specific maternal antibodies noted in this cohort mitigated the poor vaccineinduced humoral responses seen in early infancy [33]. The 
same research group also studied the impact of maternal HIV infection and demonstrated that HIV exposed, uninfected infants have normal responses to BCG vaccination administered at birth. T cell subsets are affected, however, which likely reflects priming of the developing immune system even in the absence of infection. Similarly, sensitisation to mycobacteria resulted in a positive correlation between maternal and newborn levels of BCG-specific CD4 T cells. This again suggests that maternal cellular responses may shape the infant response to BCG antigen. Following administration of BCG at 6 weeks of age, however, no difference in subsequent BCG-specific T cell proliferative responses or cytokine induction was documented at 16 weeks of age between those infants with either exposure to maternal HIV and/or latent TB [112]. Therefore, any effects of maternal HIV and possible TB infection on infant immune profiles at birth are considered transient, as long as the infant remains uninfected. Given this, HIV exposed, uninfected infants are equally likely to respond to and be protected by BCG vaccination as HIV unexposed infants [33,112]. Not all studies, however, currently agree on this conclusion. Data from two Brazilian studies suggests that HIV exposed but uninfected infants have altered T cell responses to BCG with lower TT- and HBV-specific antibody levels [113, 114].

Finally, placental malaria, secondary to maternal infection with Plasmodium falciparum or Plasmodium vivax, may impact neonatal immunity and vaccine responses. Above all, placental malaria is associated with reduced transfer of specific maternal antibodies, including RSV, varicella zoster, herpes simplex and measles and TT [115-117]. This may be due to pathological changes in the placental structure in endemic settings, with subsequent damage to $\mathrm{Fc}$ receptors [89, 115-117]. Furthermore, similar antibody and T lymphocyte responses to TT were noted in infants born to mothers with or without placental malaria [118]. Ultimately, further work is required to elucidate these effects. The mechanisms may be similar to those proposed in maternal HIV, in that the limited transfer of maternal antibody may overcome potential blunting of neonatal humoral responses to early vaccination.

\section{Neonatal co-factors}

In addition to maternal factors, genetic variation among hosts plays a key role in the observed heterogeneity of neonatal and infant vaccine responses [119]. Marchant et al. measured antibody responses to tetanus toxoid, measles and total $\operatorname{IgG}$ in 210 Gambian twin pairs, estimating the environmental versus genetic components of any variation documented. They found that genetic determinants control the early phase of the vaccine antibody response, while the environment predominantly influences antibody persistence and avidity maturation [120]. More recently, further studies have applied genome-wide association studies in order to attempt to identify the genetic determinants of different vaccine responses against hepatitis $\mathrm{B}$, measles and rubella [121].

The quantity and quality of innate and adaptive responses to newborn immunisation are further impaired in babies born prematurely. As such, the concerns regarding immunogenicity and safety are even more marked, particularly given the lack of detailed immunological studies in this age group, mainly limited by the small amounts of blood available [122, 123]. For a number of antigens, the humoral response to initial vaccine doses may be lower than that of term infants, but the protective threshold is often reached and memory successfully induced, sometimes with an additional dose to achieve persistence of protection [123]. Again, the lower titres of maternal antibodies seen in prematurity may enhance this effect. On the other hand, it is widely accepted that HBV is less immunogenic in preterm infants with birth weights $<2 \mathrm{~kg}$ than in term infants $[124,125]$. Nevertheless, unless they have underlying medical complications, these infants respond to HBV by 30 days of age regardless of birth weight or gestational age [124].

Baxter et al. concluded that immunogenicity in this cohort is vaccine specific: robust responses are seen following TT and inactive preparations; however, subunit formulations are less optimal. As such, they recommend administering additional booster doses and/or serology testing for infants $<32$ weeks [122]. Further research in this area would give important insights into the ontogeny of the maturing fetal and neonatal immune system and should be encouraged, given that novel tools are now available potentially applicable to very small volume samples.

In parallel to the significant impact of maternal coinfections and maternal-fetal disease transmission on neonatal immune responses, other co-morbidities in the newborn may have equally profound effects. One example is congenital non-infective immunodeficiency such as severe combined immunodeficiency disease (SCID). BCG vaccine has a very high rate of complications in SCID patients, as in HIV disease, with increased vaccine-associated morbidity and mortality rates [126]. Disseminated BCG infection in children is also linked to rare immunodeficiencies of the IFN $\gamma$ and IL12 pathways [50]. Furthermore, acquired infections may be important. Few studies have elucidated these interactions in the neonatal context although more work has been done in older children. Infant malaria is associated with lower IFN $\gamma$, IL5 and IL13 (i.e. Th1) responses to both BCG and tetanus immunisation [107]. In vitro incubation of monocytes with P. falciparuminfected red blood cells has been reported to lead to enhanced responsiveness to TLR ligands, which may shape neonatal immune responses [127].

\section{Environmental}

It is well established that neonatal immunity and therefore vaccine responses vary considerably across different 
geographical settings [33]. For example, Lalor et al. demonstrated that 3 months post-BCG immunisation, $100 \%$ of UK infants made an IFN $\gamma$ response to M.tb purified protein derivative (PPD), compared to $53 \%$ of Malawian infants in whom responses varied by season of birth and possibly influenced by early exposure to environmental mycobacteria, as earlier discussed. Furthermore, there was a higher Th2- and lower Th1-type response to PPD in Malawian infants compared with UK infants [128]. Similarly, Hur et al. reported that both geographical location (Malawi, Gambia and UK) and season of birth (dry vs. wet) significantly affected the cytokine profile and immunogenicity observed in response to PPD in infants at 3 months post BCG vaccination [129]. However, the type of assay used meant that it was not possible to show which cells were primarily involved in mediating these differences and the underlying mechanisms remain unclear [33].

Finally, environmental factors combined with host genetics influence bacterial colonisation after birth and the establishment of gut microbiota, regarded as crucial for optimal host immune development. This is illustrated by the finding that germ-free mice are at increased risk for infectious as well as autoimmune disease $[2,130,131]$ Currently, the impact of the microbiome on early vaccine responses is still poorly understood. In one study, TLR5-mediated sensing of the microbiota was found to drive lymph node plasma cell differentiation and enhance antibody responses to inactivated polio and influenza vaccines [132]. Moreover, it is already well known that immune responses to oral vaccines in developing countries are suboptimal, possibly related to gut dysbiosis. Huda et al. investigated if stool microbiota composition predicted infant oral (OPV) and parenteral (BCG, HBV, tetanus toxoid) vaccine responses at 6,11 and 15 weeks of age in a small group of 48 Bangladeshi infants. They demonstrated that bifidobacterium predominance may enhance thymic development and responses to both oral and parenteral vaccines early in infancy. By contrast, greater bacterial diversity may cause systemic inflammation (neutrophilia) and lower vaccine responses [133]. There is now need for similar studies in the neonatal period.

\section{The future: novel approaches to neonatal immunisation}

\section{Optimise research models}

In order to develop improved neonatal vaccines, better and more applicable research models will be required; this would enable the accurate assessment of both vaccine immunogenicity and safety $[3,5,6]$. Neonatal trials, even pilot studies, are fraught with practical and ethical challenges. Nonetheless, it is not sufficient to predict the response of human newborns to vaccines from studies of older infants or adults. Equally, although animal models, particularly neonatal ones, can provide useful insight into early life immunity, they carry inherent disadvantages which may preclude the direct translation of results and conclusions to humans [6]. Some mammalian species, including horses, pigs and ruminants, differ in the type of placentation and relative placental and colostral transfer of immunoglobulins to the fetus and newborn [134]. Similarly, the innate immune system highly varies between species (e.g. murine vs. human). The neonatal period in mice typically refers to the first 7 days of life and therefore any experiments that exceed this time period may not be applicable to human newborns [5, 6, 134].

Novel approaches to neonatal immunisation are threefold: new types of vaccine configurations (varying both mechanism of action and antigen-adjuvant formulations), new types of vaccine delivery and new types of infant immunisation strategies. These approaches aim to overcome deficiencies in neonatal innate and adaptive immune responses and thereby enable effective newborn vaccination [5]. The dynamic ability of the early immune system to balance often opposing demands, genetically encoded to maintain immune homeostasis versus environmentally driven to challenge a range of potentially pathogenic organisms, demonstrates its powerful potential for plasticity [2].

\section{Novel vaccine configurations}

The success of neonatal BCG and HBV emphasises that (1) sufficiently robust adaptive immune responses and functional, seroprotective antibody titres can be generated in the newborn period (2) this is will only occur in response to sufficiently potent antigen-adjuvant combinations and/or appropriate cellular interactions (3) ideally focus should be on potentiating innate immune signalling pathways, particularly recruiting and activating APCs, to help overcome adaptive immune deficiencies, including Th2-type skewing and dampened Th1type immunity while boosting B cell responses [32, 135]. Finding a novel vaccine type is, therefore, primarily a search for optimal antigen-adjuvant combinations that will be both effective and safe at birth. Costly antigens and multiple vaccine doses may also be avoided [5].

Adjuvants boost infant immunity through multiple mechanisms, including the following: activating innate immune responses; increasing half-life of the vaccine antigen by creating a 'depot effect'; assembling and directing antigens towards APCs, subsequently activating them; eliciting stronger mucosal responses; supporting cell-mediated immunity by enhancing cytotoxic or Th-1 type T cell function [136]. Currently alum is the only licenced adjuvant in neonates, despite studies suggesting that it does not promote robust Th1-type immunity [137] .

MF59, an oil-in-water emulsion recently being investigated for use in early life adjuvanticity, assembles antigencontaining microspheres and has been showed to have a good safety profile. In neonatal murine models, it both induces a 
'depot effect', prolonging stimulation of the vaccine antigen, and enhances APC recruitment and activity, subsequently promoting CD4+ effector T cell activity and strong B and T cell memory responses [5]. Moreover, TFH cell function is boosted which mediates B cell adjuvanticity, with secretion of persistently high and broader range of antibody levels [29].

Another approach to promoting robust $\mathrm{T}$ cell responses, including shifting the polarisation to Th1-type immunity, is to tackle neonatal APC impairment by exogenously administering co-stimulatory signals. This is particularly important if endogenous cytokine secretion is deficient or transcription within dendritic cells (DCs) is repressed, such as with IL12 [138]. As discussed earlier, IL12 is critical in mediating DC-directed T cell differentiation to TFH as well as enhancing activity of cytotoxic and Th1-type T cells. Co-administration of IL12 and influenza subunit vaccine to newborn mice led to increased splenic expression of IFN $\gamma$, IL10 and IL15 mRNA and enhanced protective efficacy of antiviral immunisation [139]. By contrast, synergistic stimulation of DCs with at least two TLR agonists demonstrates enhanced endogenous Il-12p70 production in cord blood [140]. Given its function, effective induction of IL12 is therefore a priority in vaccine design.

Most importantly, new vaccine formulations are being investigated that boost innate immunity by judicious targeting of PRRs, primarily TLRs $[79,135]$. Much interest has focused on specifically stimulating TLR3, TLR7, TLR8 and TLR9 receptors, which are located within endosomes and display robust responses to stimulation in neonates [5]. This is probably because they can utilise adenosine-refractory intracellular pathways [141]. CpG DNA, a TLR9 ligand, has been shown to increase pertussis toxoid-specific antibody secretion, along with immune defence peptides and polphasphazenes, following newborn and adult vaccination in mice [142]. Similarly, TLR8 agonists, such as certain synthetic imidazoguinolines and single-stranded viral RNA, are particularly effective at stimulating human neonatal APCs in vitro as well as eliciting TNF and IL12p40/70 secretion and promoting up-regulation of the co-stimulatory molecule CD40 [143]. Equally, these agonists may also mitigate the suppressive effects of $\mathrm{T}$ regulatory cells that induce APC tolerance and limit robust adaptive immune responses [144]. Moreover, TLR agonists mediate $\mathrm{B}$ cell adjuvanticity, with the production of high affinity $\mathrm{B}$ cell effectors, by acting on multiple innate cells including dendritic cells and enhancing TFH responses [2]. Most recently, Dowling et al. demonstrated that TLR8 agonist nanoparticles (polymersomes) mimic immunomodulatory mechanisms seen following BCG administration, for example newborn DC maturation profiles are similar to those induced by BCG but with greater IL12p70 secretion [145]. In particular, the ability to stimulate multiple TLRs simultaneously has a synergistic effect, with recent focus on combined TLR7/TLR8 stimulation to circumvent impairment of newborn APC responses. R848 (also known as imiquimod, a type of imidazogluinoline) ligates both TLR7 and TLR8 receptors simultaneously, resulting in more marked production of TNF $\alpha$ and IL- $1 \beta$ than if these sites are stimulated individually [141].

As we have seen, adjuvants in the neonatal context would primarily help to overcome functional peculiarities of neonatal APCs, thereby promoting both cell and humoral immunity. Further work is required to yield more effective, targeted interventions at PRR and particularly TLR 3/7/8/9 sites, while still monitoring for reactogenicity and potentially severe adverse effects, including development of toxicity, neurological reactions or autoimmune disease $[5,6,136]$.

Finally, establishing a novel mechanism of action may be another potentially effective strategy. In particular, DNA-based immunisation has shown promise in the context of protecting newborn mice against malaria. Vaccinated neonates, including those born to immune mothers, were noted to mount CD8+ T cell-mediated protection similar to adults [146].

\section{Novel mechanisms of vaccine delivery}

Administration of neonatal vaccinations by the mucosal route may be superior to parenteral immunisation. This is particularly true for RSV and rotavirus which are responsible for the high burden of infant respiratory and gastrointestinal diseases, respectively, worldwide. A study by Noh et al. using a murine model demonstrated that intranasal administration of RSV glycoprotein core fragment (Gcf) at birth can elicit systemic humoral immune responses and elevated IFN $\gamma$ secretion, protecting newborn mice against RSV challenge without development of lung eosinophilia, even in the presence of high RSV-specific maternal antibody titres [146].

Intracytoplasmic delivery of antigens is another novel option being considered. Indeed robust neonatal adaptive responses are dependent on the entrance of vaccine antigens in to the cytoplasm of APCs. To overcome potential blunting from maternal antibodies, Chen et al. used a neonatal murine model in the context of influenza immunisation, to show that mothers and their offspring should be vaccinated with different vaccine types targeting distinct antigens. The application of an attenuated strain of the intracellular bacterium Listeria monocytogenes to deliver heterologous antigen directly and efficiently to APC cytoplasm may also be a promising vaccine vehicle for the newborn. A strong CD8+ and CD4+ Th1 type memory response was induced, even in the presence of pre-existing maternal immunity. Importantly, this approach seemed to be safe in neonatal mice but all remains untested in human infants, given the potentially harmful effects of this pathogen [147].

\section{Combination strategies}

Recently, there has been an interest in using neonatal vaccines as primers (vs. single dose), in order to potentiate immune responses to homologous or heterologous boosters in later infancy. 
Dai et al. tested the immunogenicity of a heterologous primeboost combination against TB in neonatal mice, with the initial DNA vaccine component given intradermally soon after birth followed by a recombinant adenovirus vector vaccine encoding the same antigen and given via the intranasal route at 6 weeks of age. Results suggested that neonatal immunisation with genebased vaccines may create a favourable immunological environment that potentiates the pulmonary mucosal boosting, enhancing pulmonary $\mathrm{T}$ cell responses and therefore protection against pulmonary TB challenge [148, 149].

Combining the administration of BCG with other vaccines is already an established strategy which can enhance responses to co-delivered vaccines, as alluded to in the discussion on nonspecific effects previously. Measurements of potential vaccine interference always form part of vaccine trials prior to the introduction of a new vaccine into WHO immunisation schedules; this principle needs to be preserved for any co-administered vaccines in the neonatal period with the appropriate longer term follow-up to discover any potential knock-on effects.

Figure 1 summarises remaining gaps in knowledge and outlines research requirements for the development of the next generation of effective vaccines aimed at newborns.

\section{Conclusions}

Effective neonatal vaccination remains a global health priority as it may have both immunological and practical advantages over other protective strategies in the newborn period. Three vaccines are currently administered successfully worldwide within the first 4 weeks of life: BCG, hepatitis B vaccine and oral polio vaccine. The difference in their mechanism of action, immune responses elicited and route of delivery effectively demonstrates the potential for impact of this type of immunisation on reducing morbidity and mortality of a range of possible neonatal and infant diseases. Newborn vaccines are also a useful and safe probe into neonatal immunity: by enabling the controlled delivery of a well-defined immune challenge to the naïve newborn immune system, we can develop a more comprehensive understanding of protective mechanisms in early life.

Potential barriers to successful neonatal vaccination are multi-factorial and include the following: inherent peculiarities of newborn innate and adaptive immunity limiting vaccine immunogenicity, intrinsic immunoregulatory mechanisms, host genetic factors, prematurity, infant co-morbidities, interference from maternal antibody, chronic maternal conditions and environmental influences.

Future research must integrate lessons from early immune ontogeny and focus on developing vaccine types with novel mechanisms of action that engage with the unique neonatal immune profile (Fig. 1). Optimising antigen-adjuvant combinations in order to activate APCs and potentiate innate immunity is key. This would promote secretion of IL-12, type I interferons and Th1-type polarising cytokines subsequently inducing robust Th1-type and TFH cell responses, thereby circumventing inherent deficiencies of the newborn adaptive

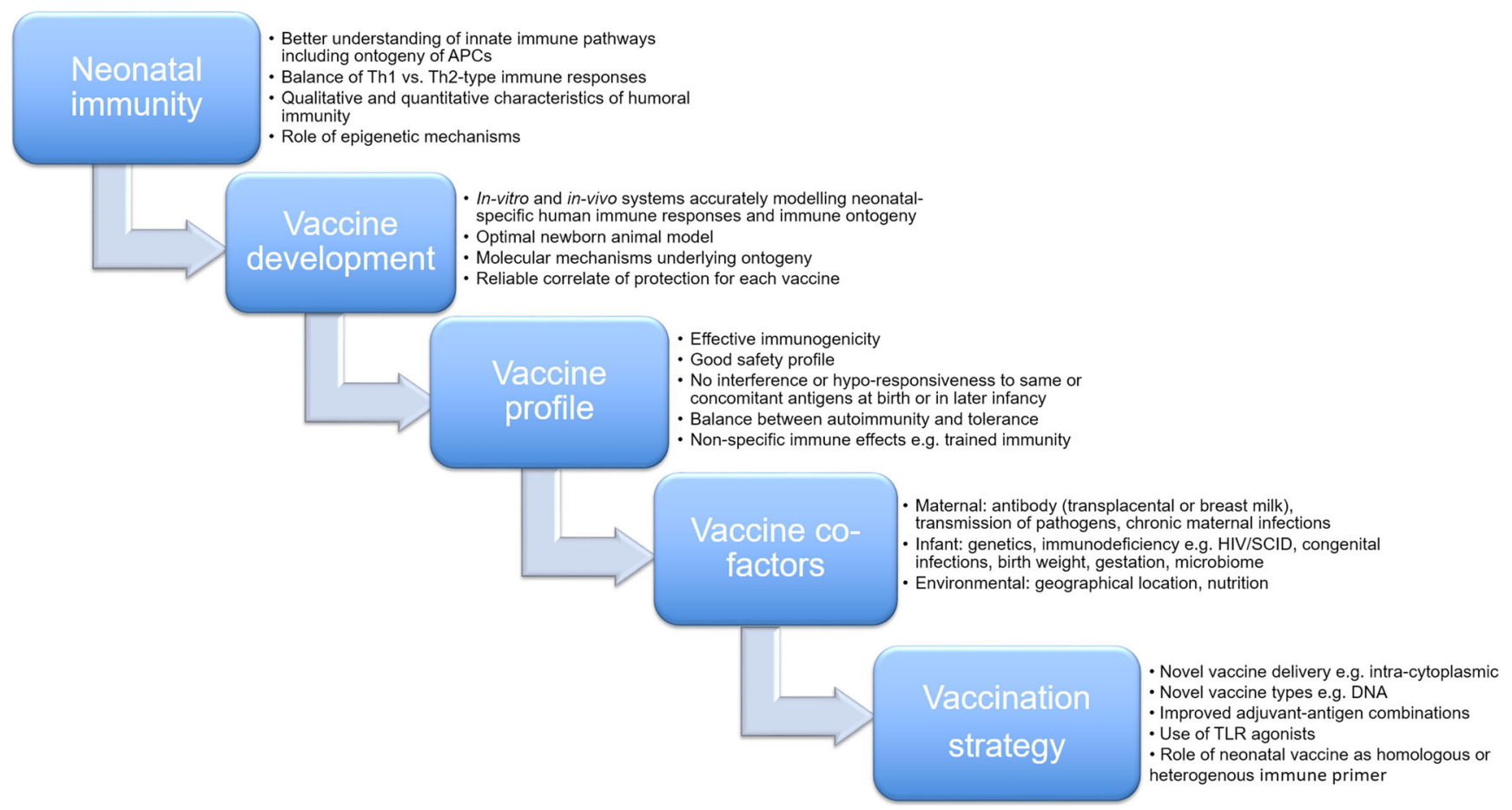

Fig. 1 Summary of topics requiring further research to support of the development of future effective vaccines for use in newborns 
immune system. Of note, a dual strategy involving newborn immune priming with subsequent homologous or heterologous boosting may be a particularly effective tool to tackle infections in early life. Rigorous and stringent safety analysis, however, must underpin all of these endeavours, including an accurate reporting system of both specific and non-specific generalised effects of novel vaccines.

Key points

- Effective neonatal vaccination remains a global health priority with the potential to significantly reduce infant morbidity and mortality.

- It is also a useful probing tool to improve our understanding of the protective innate and adaptive immune mechanisms in early life.

- Only three vaccines are currently administered in the newborn period, BCG, hepatitis B vaccine and oral polio vaccine.

- Recent advances in our understanding of immune ontogeny have resulted in a renewed interest in neonatal immunisation.

- Other infant, maternal and environmental factors may have limiting effects on vaccine-induced immune responses.

- Future strategies must overcome inherent deficiencies in neonatal immunity and address any concerns regarding vaccine immunogenicity, safety and immune interference.

Acknowledgements BK acknowledges the support by the National Institute for Health Research (NIHR) Biomedical Research Centre based at Imperial College Healthcare NHS Trust and Imperial College London and the core support from the MRC, UK to the Vaccines \& Immunity Theme at the MRC Unit in The Gambia (MC UP A900/1122). BK also acknowledges the supported by the IMmunising PRegnant women and INfants neTwork (IMPRINT), funded by the GCRF Networks in Vaccines Research and Development and co-funded by the MRC and BBSRC.

Funding We did not receive any direct financial support for the research, authorship and/or publication of this article.

\section{Compliance with ethical standards}

Conflict of interest The authors declare that they have no competing interests.

Open Access This article is distributed under the terms of the Creative Commons Attribution 4.0 International License (http:// creativecommons.org/licenses/by/4.0/), which permits unrestricted use, distribution, and reproduction in any medium, provided you give appropriate credit to the original author(s) and the source, provide a link to the Creative Commons license, and indicate if changes were made.

\section{References}

1. WHO (2015) Child mortality and causes of death. In Global Health Observatory Data, www.who.int/gho/child health/ mortality/en/. Accessed 26th June 2017

2. Kollmann TR, Kampmann B, Mazmanian SK, Marchant A, Levy O (2017) Protecting the newborn and young infant from infectious diseases: lessons from immune ontogeny. Immunity 46:350-363
3. Wood N, Siegrist CA (2011) Neonatal immunization: where do we stand? Curr Opin Infect Dis 24:190-195

4. Dowling DJ, Levy O (2014) Ontogeny of early life immunity. Trends Immunol 35:299-310

5. Morris MC, Surendran N (2016) Neonatal vaccination: challenges and intervention strategies. Neonatology 109:161-169

6. Demirjian A, Levy O (2009) Safety and efficacy of neonatal vaccination. Eur J Immunol 39:36-46

7. Day MJ (2007) Vaccine safety in the neonatal period. J Comp Pathol 137(Suppl 1):S51-S56

8. Goriely S, Goldman M (2007) From tolerance to autoimmunity: is there a risk in early life vaccination? J Comp Pathol 137(Suppl 1): S57-S61

9. Kollmann TR, Levy O, Hanekom W (2013) Vaccine-induced immunity in early life. Vaccine 31:2481-2482

10. Basha S, Surendran N, Pichichero M (2014) Immune responses in neonates. Expert Rev Clin Immunol 10:1171-1184

11. Fadel S, Sarzotti M (2000) Cellular immune responses in neonates. Int Rev Immunol 19:173-193

12. Garcia AM, Fadel SA, Cao S, Sarzotti M (2000) T cell immunity in neonates. Immunol Res 22:177-190

13. Marchant A, Goldman M (2005) T cell-mediated immune responses in human newborns: ready to learn? Clin Exp Immunol 141:10-18

14. Debock I, Flamand V (2014) Unbalanced neonatal CD4(+) T cell immunity. Front Immunol 5:393

15. PrabhuDas M, Adkins B, Gans H, King C, Levy O, Ramilo O, Siegrist CA (2011) Challenges in infant immunity: implications for responses to infection and vaccines. Nat Immunol 12:189-194

16. Siegrist CA (2007) The challenges of vaccine responses in early life: selected examples. J Comp Pathol 137(Suppl 1):S4-S9

17. Fink PJ (2013) The biology of recent thymic emigrants. Annu Rev Immunol 31:31-50

18. Haines CJ, Giffon TD, Lu LS, Lu X, Tessier-Lavigne M, Ross DT, Lewis DB (2009) Human CD4+ T cell recent thymic emigrants are identified by protein tyrosine kinase 7 and have reduced immune function. J Exp Med 206:275-285

19. White GP, Watt PM, Holt BJ, Holt PG (2002) Differential patterns of methylation of the IFN-gamma promoter at $\mathrm{CpG}$ and non-CpG sites underlie differences in IFN-gamma gene expression between human neonatal and adult CD45RO- T cells. J Immunol 168: 2820-2827

20. Ma CS, Suryani S, Avery DT, Chan A, Nanan R, Santner-Nanan B, Deenick EK, Tangye SG (2009) Early commitment of naive human CD4(+) T cells to the T follicular helper $(\mathrm{T}(\mathrm{FH})$ ) cell lineage is induced by IL-12. Immunol Cell Biol 87:590-600

21. Zaghouani H, Hoeman CM, Adkins B (2009) Neonatal immunity: faulty T-helpers and the shortcomings of dendritic cells. Trends Immunol 30:585-591

22. Boer MC, Joosten SA, Ottenhoff TH (2015) Regulatory T-cells at the interface between human host and pathogens in infectious diseases and vaccination. Front Immunol 6:217

23. Burt TD (2013) Fetal regulatory T cells and peripheral immune tolerance in utero: implications for development and disease. Am J Reprod Immunol 69:346-358

24. Kollmann TR, Levy O, Montgomery RR, Goriely S (2012) Innate immune function by Toll-like receptors: distinct responses in newborns and the elderly. Immunity 37:771-783

25. Siegrist CA, Aspinall R (2009) B-cell responses to vaccination at the extremes of age. Nat Rev Immunol 9:185-194

26. Debock I, Jaworski K, Chadlaoui H, Delbauve S, Passon N, Twyffels L, Leo O, Flamand V (2013) Neonatal follicular Th cell responses are impaired and modulated by IL-4. J Immunol 191: 1231-1239

27. Mastelic B, Kamath AT, Fontannaz P, Tougne C, Rochat AF, Belnoue E, Combescure C, Auderset F, Lambert PH, Tacchini- 
Cottier F, Siegrist CA (2012) Environmental and T cell-intrinsic factors limit the expansion of neonatal follicular $\mathrm{T}$ helper cells but may be circumvented by specific adjuvants. J Immunol 189: 5764-5772

28. Pihlgren M, Tougne C, Bozzotti P, Fulurija A, Duchosal MA, Lambert PH, Siegrist CA (2003) Unresponsiveness to lymphoidmediated signals at the neonatal follicular dendritic cell precursor level contributes to delayed germinal center induction and limitations of neonatal antibody responses to T-dependent antigens. J Immunol 170:2824-2832

29. Mastelic Gavillet B, Eberhardt CS, Auderset F, Castellino F, Seubert A, Tregoning JS, Lambert PH, de Gregorio E, Del Giudice G, Siegrist CA (2015) MF59 mediates its B cell adjuvanticity by promoting $\mathrm{T}$ follicular helper cells and thus germinal center responses in adult and early life. J Immunol 194: 4836-4845

30. Levy O, Coughlin M, Cronstein BN, Roy RM, Desai A, Wessels MR (2006) The adenosine system selectively inhibits TLRmediated TNF-alpha production in the human newborn. J Immunol 177:1956-1966

31. Levy O (2007) Innate immunity of the newborn: basic mechanisms and clinical correlates. Nat Rev Immunol 7:379-390

32. Iwasaki A, Medzhitov R (2015) Control of adaptive immunity by the innate immune system. Nat Immunol 16:343-353

33. Kampmann B, Jones CE (2015) Factors influencing innate immunity and vaccine responses in infancy. Philos Trans R Soc Lond Ser B Biol Sci 19;370(1671)

34. Corbett NP, Blimkie D, Ho KC, Cai B, Sutherland DP, Kallos A, Crabtree J, Rein-Weston A, Lavoie PM, Turvey SE, Hawkins NR, Self SG, Wilson CB, Hajjar AM, Fortuno ES 3rd, Kollmann TR (2010) Ontogeny of Toll-like receptor mediated cytokine responses of human blood mononuclear cells. PLoS One 5:e15041

35. Levy O (2005) Innate immunity of the human newborn: distinct cytokine responses to LPS and other Toll-like receptor agonists. J Endotoxin Res 11:113-116

36. Ota MO, Vekemans J, Schlegel-Haueter SE, Fielding K, Whittle H, Lambert PH, McAdam KP, Siegrist CA, Marchant A (2004) Hepatitis B immunisation induces higher antibody and memory Th2 responses in new-borns than in adults. Vaccine 22:511-519

37. Vekemans J, Ota MO, Wang EC, Kidd M, Borysiewicz LK, Whittle H, McAdam KP, Morgan G, Marchant A (2002) T cell responses to vaccines in infants: defective IFNgamma production after oral polio vaccination. Clin Exp Immunol 127:495-498

38. Ota MO, Vekemans J, Schlegel-Haueter SE, Fielding K, Sanneh M, Kidd M, Newport MJ, Aaby P, Whittle H, Lambert PH, McAdam KP, Siegrist CA, Marchant A (2002) Influence of Mycobacterium bovis bacillus Calmette-Guerin on antibody and cytokine responses to human neonatal vaccination. J Immunol 168:919-925

39. Siegrist CA (2008) Blame vaccine interference, not neonatal immunization, for suboptimal responses after neonatal diphtheria, tetanus, and acellular pertussis immunization. J Pediatr 153:305307

40. Halasa NB, O'Shea A, Shi JR, LaFleur BJ, Edwards KM (2008) Poor immune responses to a birth dose of diphtheria, tetanus, and acellular pertussis vaccine. J Pediatr 153:327-332

41. Knuf M, Schmitt HJ, Wolter J, Schuerman L, Jacquet JM, Kieninger D, Siegrist CA, Zepp F (2008) Neonatal vaccination with an acellular pertussis vaccine accelerates the acquisition of pertussis antibodies in infants. J Pediatr 152:655-660 60.e1

42. Knuf M, Schmitt HJ, Jacquet JM, Collard A, Kieninger D, Meyer CU, Siegrist CA, Zepp F (2010) Booster vaccination after neonatal priming with acellular pertussis vaccine. J Pediatr 156:675-678

43. Nissen TN, Birk NM, Smits G, Jeppesen DL, Stensballe LG, Netea MG, van der Klis F, Benn CS, Pryds O (2017) Bacille Calmette-Guerin (BCG) vaccination at birth and antibody responses to childhood vaccines. A randomised clinical trial. Vaccine 35:2084-2091

44. Halsey N, Galazka A (1985) The efficacy of DPT and oral poliomyelitis immunization schedules initiated from birth to 12 weeks of age. Bull World Health Organ 63:1151-1169

45. Trunz BB, Fine P, Dye C (2006) Effect of BCG vaccination on childhood tuberculous meningitis and miliary tuberculosis worldwide: a meta-analysis and assessment of cost-effectiveness. Lancet 367:1173-1180

46. Roy A, Eisenhut M, Harris RJ, Rodrigues LC, Sridhar S, Habermann S, Snell L, Mangtani P, Adetifa I, Lalvani A, Abubakar I (2014) Effect of BCG vaccination against Mycobacterium tuberculosis infection in children: systematic review and meta-analysis. BMJ 349:g4643

47. Fletcher HA (2007) Correlates of immune protection from tuberculosis. Curr Mol Med 7:319-325

48. Clemens JD, Chuong JJ, Feinstein AR (1983) The BCG controversy. A methodological and statistical reappraisal. JAMA 249: 2362-2369

49. Colditz GA, Berkey CS, Mosteller F, Brewer TF, Wilson ME, Burdick E, Fineberg HV (1995) The efficacy of bacillus Calmette-Guerin vaccination of newborns and infants in the prevention of tuberculosis: meta-analyses of the published literature. Pediatrics 96:29-35

50. Remus N, Reichenbach J, Picard C, Rietschel C, Wood P, Lammas D, Kumararatne DS, Casanova JL (2001) Impaired interferon gamma-mediated immunity and susceptibility to mycobacterial infection in childhood. Pediatr Res 50:8-13

51. Fine PE (1995) Variation in protection by BCG: implications of and for heterologous immunity. Lancet 346:1339-1345

52. Heldwein KA, Liang MD, Andresen TK, Thomas KE, Marty AM, Cuesta N, Vogel SN, Fenton MJ (2003) TLR2 and TLR4 serve distinct roles in the host immune response against Mycobacterium bovis BCG. J Leukoc Biol 74:277-286

53. Mangtani P, Abubakar I, Ariti C, Beynon R, Pimpin L, Fine PE, Rodrigues LC, Smith PG, Lipman M, Whiting PF, Sterne JA (2014) Protection by BCG vaccine against tuberculosis: a systematic review of randomized controlled trials. Clin Infect Dis 58: 470-480

54. Marchant A, Goetghebuer T, Ota MO, Wolfe I, Ceesay SJ, De Groote D, Corrah T, Bennett S, Wheeler J, Huygen K, Aaby P, McAdam KP, Newport MJ (1999) Newborns develop a Th1-type immune response to Mycobacterium bovis bacillus CalmetteGuerin vaccination. J Immunol 163:2249-2255

55. Soares AP, Kwong Chung CK, Choice T, Hughes EJ, Jacobs G, van Rensburg EJ, Khomba G, de Kock M, Lerumo L, Makhethe L, Maneli MH, Pienaar B, Smit E, Tena-Coki NG, van Wyk L, Boom WH, Kaplan G, Scriba TJ, Hanekom WA (2013) Longitudinal changes in CD4(+) T-cell memory responses induced by BCG vaccination of newborns. J Infect Dis 207:1084 1094

56. Kagina BM, Abel B, Scriba TJ, Hughes EJ, Keyser A, Soares A, Gamieldien H, Sidibana M, Hatherill M, Gelderbloem S, Mahomed H, Hawkridge A, Hussey G, Kaplan G, Hanekom WA (2010) Specific T cell frequency and cytokine expression profile do not correlate with protection against tuberculosis after bacillus Calmette-Guerin vaccination of newborns. Am J Respir Crit Care Med 182:1073-1079

57. Aaby P, Benn CS (2011) Non-specific and sex-differential effects of routine vaccines: what evidence is needed to take these effects into consideration in low-income countries? Hum Vaccin 7:120 124

58. Cavallo GP, Elia M, Giordano D, Baldi C, Cammarota R (2002) Decrease of specific and total IgE levels in allergic patients after BCG vaccination: preliminary report. Arch Otolaryngol Head Neck Surg 128:1058-1060 
59. de Castro MJ, Pardo-Seco J, Martinon-Torres F (2015) Nonspecific (heterologous) protection of neonatal BCG vaccination against hospitalization due to respiratory infection and sepsis. Clin Infect Dis 60:1611-1619

60. Freyne B, Marchant A, Curtis N (2015) BCG-associated heterologous immunity, a historical perspective: intervention studies in animal models of infectious diseases. Trans R Soc Trop Med Hyg 109:52-61

61. Garly ML, Martins CL, Bale C, Balde MA, Hedegaard KL, Gustafson P, Lisse IM, Whittle HC, Aaby P (2003) BCG scar and positive tuberculin reaction associated with reduced child mortality in West Africa. A non-specific beneficial effect of BCG? Vaccine 21:2782-2790

62. Goodridge HS, Ahmed SS, Curtis N, Kollmann TR, Levy O, Netea MG, Pollard AJ, van Crevel R, Wilson CB (2016) Harnessing the beneficial heterologous effects of vaccination. Nat Rev Immunol 16:392-400

63. Fine PE, Smith PG, Evans SJ (2012) Non-specific effects of BCG? J Infect Dis 205:515 author reply 7-8

64. Stensballe LG, Sorup S, Aaby P, Benn CS, Greisen G, Jeppesen DL, Birk NM, Kjaergaard J, Nissen TN, Pihl GT, Thostesen LM, Kofoed PE, Pryds O, Ravn H (2017) BCG vaccination at birth and early childhood hospitalisation: a randomised clinical multicentre trial. Arch Dis Child 102:224-231

65. Kandasamy R, Voysey M, McQuaid F, de Nie K, Ryan R, Orr O, Uhlig U, Sande C, O'Connor D, Pollard AJ (2016) Non-specific immunological effects of selected routine childhood immunisations: systematic review. BMJ 355:i5225

66. Pollard AJ, Finn A, Curtis N (2017) Non-specific effects of vaccines: plausible and potentially important, but implications uncertain. Arch Dis Child

67. Ritz N, Mui M, Balloch A, Curtis N (2013) Non-specific effect of Bacille Calmette-Guerin vaccine on the immune response to routine immunisations. Vaccine 31:3098-3103

68. Ifrim DC, Quintin J, Joosten LA, Jacobs C, Jansen T, Jacobs L, Gow NA, Williams DL, van der Meer JW, Netea MG (2014) Trained immunity or tolerance: opposing functional programs induced in human monocytes after engagement of various pattern recognition receptors. Clin Vaccine Immunol 21:534-545

69. Levy O, Levy O (2015) Ready to benefit from training: heterologous effects of early life immunization. Trans R Soc Trop Med Hyg 109:3-4

70. Levy O, Netea MG (2014) Innate immune memory: implications for development of pediatric immunomodulatory agents and adjuvanted vaccines. Pediatr Res 75:184-188

71. Kleinnijenhuis J, Quintin J, Preijers F, Joosten LA, Ifrim DC, Saeed S, Jacobs C, van Loenhout J, de Jong D, Stunnenberg HG, Xavier RJ, van der Meer JW, van Crevel R, Netea MG (2012) Bacille Calmette-Guerin induces NOD2-dependent nonspecific protection from reinfection via epigenetic reprogramming of monocytes. Proc Natl Acad Sci U S A 109:17537-17542

72. Kleinnijenhuis J, Quintin J, Preijers F, Joosten LA, Jacobs C, Xavier RJ, van der Meer JW, van Crevel R, Netea MG (2014) BCG-induced trained immunity in NK cells: role for non-specific protection to infection. Clin Immunol 155:213-219

73. Djuardi Y, Sartono E, Wibowo H, Supali T, Yazdanbakhsh M (2010) A longitudinal study of BCG vaccination in early childhood: the development of innate and adaptive immune responses. PLoS One 5:e14066

74. Welsh RM, Selin LK (2002) No one is naive: the significance of heterologous T-cell immunity. Nat Rev Immunol 2:417-426

75. Gerlich WH (2015) Prophylactic vaccination against hepatitis B: achievements, challenges and perspectives. Med Microbiol Immunol 204:39-55

76. Wong VC, Ip HM, Reesink HW, Lelie PN, Reerink-Brongers EE, Yeung CY, Ma HK (1984) Prevention of the HBsAg carrier state in newborn infants of mothers who are chronic carriers of $\mathrm{HBsAg}$ and $\mathrm{HBeAg}$ by administration of hepatitis-B vaccine and hepatitisB immunoglobulin. Double-blind randomised placebo-controlled study. Lancet 1:921-926

77. Xu ZY, Liu CB, Francis DP, Purcell RH, Gun ZL, Duan SC, Chen RJ, Margolis HS, Huang CH, Maynard JE (1985) Prevention of perinatal acquisition of hepatitis $\mathrm{B}$ virus carriage using vaccine: preliminary report of a randomized, double-blind placebo-controlled and comparative trial. Pediatrics 76:713-718

78. WHO (2017) Poliomyletis. In International travel and health. http://www.who.int/ith/vaccines/polio/en/. Accessed 26th June 2017

79. Philbin VJ, Levy O (2007) Immunostimulatory activity of Tolllike receptor 8 agonists towards human leucocytes: basic mechanisms and translational opportunities. Biochem Soc Trans 35: 1485-1491

80. el-Sayed N, el-Gamal Y, Abbassy AA, Seoud I, Salama M, Kandeel A, Hossny E, Shawky A, Hussein HA, Pallansch MA, van der Avoort HG, Burton AH, Sreevatsava M, Malankar P, Wahdan MH, Sutter RW (2008) Monovalent type 1 oral poliovirus vaccine in newborns. N Engl J Med 359:1655-1665

81. Scott JA, Ojal J, Ashton L, Muhoro A, Burbidge P, Goldblatt D (2011) Pneumococcal conjugate vaccine given shortly after birth stimulates effective antibody concentrations and primes immunological memory for sustained infant protection. Clin Infect Dis 53: 663-670

82. Clarke E, Kampmann B, Goldblatt D (2016) Maternal and neonatal pneumococcal vaccination - where are we now? Expert Rev Vaccines 15:1305-1317

83. Pomat WS, van den Biggelaar AH, Phuanukoonnon S, Francis J, Jacoby P, Siba PM, Alpers MP, Reeder JC, Holt PG, Richmond PC, Lehmann D (2013) Safety and immunogenicity of neonatal pneumococcal conjugate vaccination in Papua New Guinean children: a randomised controlled trial. PLoS One 8:e56698

84. Provenzano RW, Wetterlow LH, Sullivan CL (1965) Immunization and antibody response in the newborn infant. I. Pertussis inoculation within twenty-four hours of birth. N Engl J Med 273:959-965

85. Locht C (2016) Pertussis: acellular, whole-cell, new vaccines, what to choose? Expert Rev Vaccines 15:671-673

86. Locht C, Mielcarek N (2012) New pertussis vaccination approaches: en route to protect newborns? FEMS Immunol Med Microbiol 66:121-133

87. Belloni C, De Silvestri A, Tinelli C, Avanzini MA, Marconi M, Strano F, Rondini G, Chirico G (2003) Immunogenicity of a threecomponent acellular pertussis vaccine administered at birth. Pediatrics 111:1042-1045

88. Wood N, McIntyre P, Marshall H, Roberton D (2010) Acellular pertussis vaccine at birth and one month induces antibody responses by two months of age. Pediatr Infect Dis J 29:209-215

89. Saso A, Kampmann B (2016) Vaccination against respiratory syncytial virus in pregnancy: a suitable tool to combat global infant morbidity and mortality? Lancet Infect Dis 16:e153-e163

90. Saleh E, Eichner B, Clark DW, Gagliano ME, Troutman JM, Harrington L, McNeal M, Clements D (2017) Open-label pilot study to compare the safety and immunogenicity of pentavalent rotavirus vaccine (RV5) administered on an early alternative dosing schedule with those of RV5 administered on the recommended standard schedule. J Pediatric Infect Dis Soc 3. https://doi.org/10. 1093/jpids/pix005

91. Morein B, Blomqvist G, Hu K (2007) Immune responsiveness in the neonatal period. J Comp Pathol 137(Suppl 1):S27-S31

92. Siegrist CA (2003) Mechanisms by which maternal antibodies influence infant vaccine responses: review of hypotheses and definition of main determinants. Vaccine 21:3406-3412 
93. Caceres VM, Strebel PM, Sutter RW (2000) Factors determining prevalence of maternal antibody to measles virus throughout infancy: a review. Clin Infect Dis 31:110-119

94. Pyzik M, Rath T, Lencer WI, Baker K, Blumberg RS (2015) FcRn: the architect behind the immune and nonimmune functions of IgG and albumin. J Immunol 194:4595-4603

95. Moon SS, Wang Y, Shane AL, Nguyen T, Ray P, Dennehy P, Baek LJ, Parashar U, Glass RI, Jiang B (2010) Inhibitory effect of breast milk on infectivity of live oral rotavirus vaccines. Pediatr Infect Dis J 29:919-923

96. Dorea JG (2012) Breast-feeding and responses to infant vaccines: constitutional and environmental factors. Am J Perinatol 29:759775

97. Chen MY, Kirkwood CD, Bines J, Cowley D, Pavlic D, Lee KJ, Orsini F, Watts E, Barnes G, Danchin M (2017) Rotavirus specific maternal antibodies and immune response to RV3-BB neonatal rotavirus vaccine in New Zealand. Hum Vaccin Immunother 13: $1126-1135$

98. Ali A, Kazi AM, Cortese MM, Fleming JA, Moon S, Parashar UD, Jiang B, McNeal MM, Steele D, Bhutta Z, Zaidi AK (2015) Impact of withholding breastfeeding at the time of vaccination on the immunogenicity of oral rotavirus vaccine - a randomized trial. PLoS One 10:e127622

99. Hesseling AC, Johnson LF, Jaspan H, Cotton MF, Whitelaw A, Schaaf HS, Fine PE, Eley BS, Marais BJ, Nuttall J, Beyers N, Godfrey-Faussett P (2009) Disseminated bacille CalmetteGuerin disease in HIV-infected South African infants. Bull World Health Organ 87:505-511

100. Hesseling AC, Rabie H, Marais BJ, Manders M, Lips M, Schaaf HS, Gie RP, Cotton MF, van Helden PD, Warren RM, Beyers N (2006) Bacille Calmette-Guerin vaccine-induced disease in HIVinfected and HIV-uninfected children. Clin Infect Dis 42:548-558

101. Dauby N, Goetghebuer T, Kollmann TR, Levy J, Marchant A (2012) Uninfected but not unaffected: chronic maternal infections during pregnancy, fetal immunity, and susceptibility to postnatal infections. Lancet Infect Dis 12:330-340

102. Lisciandro JG, van den Biggelaar AH (2010) Neonatal immune function and inflammatory illnesses in later life: lessons to be learnt from the developing world? Clin Exp Allergy 40:1719-1731

103. Malhotra I, Ouma J, Wamachi A, Kioko J, Mungai P, Omollo A, Elson L, Koech D, Kazura JW, King CL (1997) In utero exposure to helminth and mycobacterial antigens generates cytokine responses similar to that observed in adults. J Clin Invest 99: $1759-1766$

104. van Riet E, Hartgers FC, Yazdanbakhsh M (2007) Chronic helminth infections induce immunomodulation: consequences and mechanisms. Immunobiology 212:475-490

105. Malhotra Iea (2010) Antenatal helminth infections are associated with impaired Hib vaccine efficiency in Kenyan infants. In: Keystone symposia: immmunological mechanisms of vaccination. Seattle, WA

106. Malhotra I, Mungai P, Wamachi A, Kioko J, Ouma JH, Kazura JW, King CL (1999) Helminth- and Bacillus Calmette-Guerininduced immunity in children sensitized in utero to filariasis and schistosomiasis. J Immunol 162:6843-6848

107. Elliott AM, Mawa PA, Webb EL, Nampijja M, Lyadda N, Bukusuba J, Kizza M, Namujju PB, Nabulime J, Ndibazza J, Muwanga M, Whitworth JA (2010) Effects of maternal and infant co-infections, and of maternal immunisation, on the infant response to BCG and tetanus immunisation. Vaccine 29:247-255

108. Dauby N, Alonso-Vega C, Suarez E, Flores A, Hermann E, Cordova M, Tellez T, Torrico F, Truyens C, Carlier Y (2009) Maternal infection with Trypanosoma cruzi and congenital Chagas disease induce a trend to a type 1 polarization of infant immune responses to vaccines. PLoS Neg1 Trop Dis 3:e571
109. Mansoor N, Scriba TJ, de Kock M, Tameris M, Abel B, Keyser A, Little F, Soares A, Gelderbloem S, Mlenjeni S, Denation L, Hawkridge A, Boom WH, Kaplan G, Hussey GD, Hanekom WA (2009) HIV-1 infection in infants severely impairs the immune response induced by Bacille Calmette-Guerin vaccine. $\mathrm{J}$ Infect Dis 199:982-990

110. Helfand RF, Witte D, Fowlkes A, Garcia P, Yang C, Fudzulani R, Walls L, Bae S, Strebel P, Broadhead R, Bellini WJ, Cutts F (2008) Evaluation of the immune response to a 2-dose measles vaccination schedule administered at 6 and 9 months of age to HIVinfected and HIV-uninfected children in Malawi. J Infect Dis 198:1457-1465

111. Jones CE, Naidoo S, De Beer C, Esser M, Kampmann B, Hesseling AC (2011) Maternal HIV infection and antibody responses against vaccine-preventable diseases in uninfected infants. JAMA 305:576-584

112. Jones CE, Hesseling AC, Tena-Coki NG, Scriba TJ, Chegou NN, Kidd M, Wilkinson RJ, Kampmann B (2015) The impact of HIV exposure and maternal Mycobacterium tuberculosis infection on infant immune responses to bacille Calmette-Guerin vaccination. AIDS 29:155-165

113. Mazzola TN, da Silva MT, Abramczuk BM, Moreno YM, Lima SC, Zorzeto TQ, Passeto AS, Vilela MM (2011) Impaired Bacillus Calmette-Guerin cellular immune response in HIV-exposed, uninfected infants. AIDS 25:2079-2087

114. Abramczuk BM, Mazzola TN, Moreno YM, Zorzeto TQ, Quintilio W, Wolf PS, Blotta MH, Morcillo AM, da Silva MT, Dos Santos Vilela MM (2011) Impaired humoral response to vaccines among HIV-exposed uninfected infants. Clin Vaccine Immunol 18:1406-1409

115. Okoko BJ, Wesumperuma LH, Ota MO, Pinder M, Banya W, Gomez SF, McAdam KP, Hart AC (2001) The influence of placental malaria infection and maternal hypergammaglobulinemia on transplacental transfer of antibodies and IgG subclasses in a rural West African population. J Infect Dis 184:627-632

116. Okoko BJ, Wesuperuma LH, Ota MO, Banya WA, Pinder M, Gomez FS, Osinusi K, Hart AC (2001) Influence of placental malaria infection and maternal hypergammaglobulinaemia on materno-foetal transfer of measles and tetanus antibodies in a rural West African population. J Health Popul Nutr 19:59-65

117. Cumberland P, Shulman CE, Maple PA, Bulmer JN, Dorman EK, Kawuondo K, Marsh K, Cutts FT (2007) Maternal HIV infection and placental malaria reduce transplacental antibody transfer and tetanus antibody levels in newborns in Kenya. J Infect Dis 196: 550-557

118. Ned RM, Price AE, Crawford SB, Ayisi JG, van Eijk AM, Otieno JA, Nahlen BL, Steketee RW, Slutsker L, Shi YP, Lanar DE, Udhayakumar V (2008) Effect of placental malaria and HIV infection on the antibody responses to Plasmodium falciparum in infants. J Infect Dis 198:1609-1619

119. Newport MJ, Goetghebuer T, Weiss HA, Whittle H, Siegrist CA, Marchant A (2004) Genetic regulation of immune responses to vaccines in early life. Genes Immun 5:122-129

120. Marchant A, Pihlgren M, Goetghebuer T, Weiss HA, Ota MO, Schlegel-Hauter SE, Whittle H, Lambert PH, Newport MJ, Siegrist CA (2006) Predominant influence of environmental determinants on the persistence and avidity maturation of antibody responses to vaccines in infants. J Infect Dis 193:1598-1605

121. Mentzer AJ, O'Connor D, Pollard AJ, Hill AV (2015) Searching for the human genetic factors standing in the way of universally effective vaccines. Philos Trans R Soc Lond Ser B Biol Sci 19;370(1671)

122. Baxter D (2010) Premature infants and vaccination. Hum Vaccin 6:493

123. Bonhoeffer J, Siegrist CA, Heath PT (2006) Immunisation of premature infants. Arch Dis Child 91:929-935 
124. Blondheim O, Bader D, Abend M, Peniakov M, Reich D, Potesman I, Handsher R, Gidoni I, Linder N (1998) Immunogenicity of hepatitis B vaccine in preterm infants. Arch Dis Child Fetal Neonatal Ed 79:F206-F208

125. Linder N, Vishne TH, Levin E, Handsher R, Fink-Kremer I, Waldman D, Levine A, Ashkenazi S, Sirota L (2002) Hepatitis $B$ vaccination: long-term follow-up of the immune response of preterm infants and comparison of two vaccination protocols. Infection 30:136-139

126. Marciano BE, Huang CY, Joshi G, Rezaei N, Carvalho BC, Allwood Z, Ikinciogullari A, Reda SM, Gennery A, Thon V, Espinosa-Rosales F, Al-Herz W, Porras O, Shcherbina A, Szaflarska A, Kilic S, Franco JL, Gomez Raccio AC, Roxo P Jr, Esteves I, Galal N, Grumach AS, Al-Tamemi S, Yildiran A, Orellana JC, Yamada M, Morio T, Liberatore D, Ohtsuka Y, Lau YL, Nishikomori R, Torres-Lozano C, Mazzucchelli JT, Vilela MM, Tavares FS, Cunha L, Pinto JA, Espinosa-Padilla SE, Hernandez-Nieto L, Elfeky RA, Ariga T, Toshio H, Dogu F, Cipe F, Formankova R, Nunez-Nunez ME, Bezrodnik L, Marques JG, Pereira MI, Listello V, Slatter MA, Nademi Z, Kowalczyk D, Fleisher TA, Davies G, Neven B, Rosenzweig SD (2014) BCG vaccination in patients with severe combined immunodeficiency: complications, risks, and vaccination policies. J Allergy Clin Immunol 133:1134-1141

127. Hartgers FC, Obeng BB, Voskamp A, Larbi IA, Amoah AS, Luty AJ, Boakye D, Yazdanbakhsh M (2008) Enhanced Toll-like receptor responsiveness associated with mitogen-activated protein kinase activation in Plasmodium falciparum-infected children. Infect Immun 76:5149-5157

128. Lalor MK, Ben-Smith A, Gorak-Stolinska P, Weir RE, Floyd S, Blitz R, Mvula H, Newport MJ, Branson K, McGrath N, Crampin AC, Fine PE, Dockrell HM (2009) Population differences in immune responses to Bacille Calmette-Guerin vaccination in infancy. J Infect Dis 199:795-800

129. Hur YG, Gorak-Stolinska P, Lalor MK, Mvula H, Floyd S, Raynes J, Ben-Smith A, Fitchett JR, Flanagan KL, Burl S, Ota MO, Crampin AC, Smith SG, Dockrell HM (2014) Factors affecting immunogenicity of BCG in infants, a study in Malawi, The Gambia and the UK. BMC Infect Dis 14:184

130. Arrieta MC, Stiemsma LT, Amenyogbe N, Brown EM, Finlay B (2014) The intestinal microbiome in early life: health and disease. Front Immunol 5:427

131. Chu H, Mazmanian SK (2013) Innate immune recognition of the microbiota promotes host-microbial symbiosis. Nat Immunol 14: $668-675$

132. Oh JZ, Ravindran R, Chassaing B, Carvalho FA, Maddur MS, Bower M, Hakimpour P, Gill KP, Nakaya HI, Yarovinsky F, Sartor RB, Gewirtz AT, Pulendran B (2014) TLR5-mediated sensing of gut microbiota is necessary for antibody responses to seasonal influenza vaccination. Immunity 41:478-492

133. Huda MN, Lewis Z, Kalanetra KM, Rashid M, Ahmad SM, Raqib R, Qadri F, Underwood MA, Mills DA, Stephensen CB (2014) Stool microbiota and vaccine responses of infants. Pediatrics 134: e362-e372

134. Chappuis G (1998) Neonatal immunity and immunisation in early age: lessons from veterinary medicine. Vaccine 16:1468-1472
135. de Brito CA, Goldoni AL, Sato MN (2009) Immune adjuvants in early life: targeting the innate immune system to overcome impaired adaptive response. Immunotherapy 1:883-895

136. Sanchez-Schmitz G, Levy O (2011) Development of newborn and infant vaccines. Sci Transl Med 3:90ps27

137. Marrack P, McKee AS, Munks MW (2009) Towards an understanding of the adjuvant action of aluminium. Nat Rev Immunol 9: 287-293

138. Goriely S, Van Lint C, Dadkhah R, Libin M, De Wit D, Demonte D, Willems F, Goldman M (2004) A defect in nucleosome remodeling prevents IL-12(p35) gene transcription in neonatal dendritic cells. J Exp Med 199:1011-1016

139. Arulanandam BP, Mittler JN, Lee WT, O'Toole M, Metzger DW (2000) Neonatal administration of IL-12 enhances the protective efficacy of antiviral vaccines. J Immunol 164:3698-3704

140. Krumbiegel D, Zepp F, Meyer CU (2007) Combined Toll-like receptor agonists synergistically increase production of inflammatory cytokines in human neonatal dendritic cells. Hum Immunol 68:813-822

141. Philbin VJ, Dowling DJ, Gallington LC, Cortes G, Tan Z, Suter EE, Chi KW, Shuckett A, Stoler-Barak L, Tomai M, Miller RL, Mansfield K, Levy O (2012) Imidazoquinoline Toll-like receptor 8 agonists activate human newborn monocytes and dendritic cells through adenosine-refractory and caspase-1-dependent pathways. J Allergy Clin Immunol 130:195-204.e9

142. Gracia A, Polewicz M, Halperin SA, Hancock RE, Potter AA, Babiuk LA, Gerdts V (2011) Antibody responses in adult and neonatal BALB/c mice to immunization with novel Bordetella pertussis vaccine formulations. Vaccine 29:1595-1604

143. Levy O, Suter EE, Miller RL, Wessels MR (2006) Unique efficacy of Toll-like receptor 8 agonists in activating human neonatal antigen-presenting cells. Blood 108:1284-1290

144. Peng G, Guo Z, Kiniwa Y, Voo KS, Peng W, Fu T, Wang DY, Li Y, Wang HY, Wang RF (2005) Toll-like receptor 8-mediated reversal of CD4+ regulatory T cell function. Science 309:1380-1384

145. Dowling DJ, Scott EA, Scheid A, Bergelson I, Joshi S, Pietrasanta C, Brightman S, Sanchez-Schmitz G, Van Haren SD, Ninkovic J, Kats D, Guiducci C, de Titta A, Bonner DK, Hirosue S, Swartz MA, Hubbell JA, Levy O (2017) Toll-like receptor 8 agonist nanoparticles mimic immunomodulating effects of the live BCG vaccine and enhance neonatal innate and adaptive immune responses. J Allergy Clin Immunol pii: S0091-6749(17)30242-7. https://doi. org/10.1016/j.jaci.2016.12.985

146. Noh Y, Shim BS, Cheon IS, Rho S, Kim HJ, Choi Y, Kang CY, Chang J, Song MK, Kim JO (2013) Neonatal immunization with respiratory syncytial virus glycoprotein fragment induces protective immunity in the presence of maternal antibodies in mice. Viral Immunol 26:268-276

147. Liang ZZ, Sherrid AM, Wallecha A, Kollmann TR (2014) Listeria monocytogenes: a promising vehicle for neonatal vaccination. Hum Vaccin Immunother 10:1036-1046

148. Dai G, Rady HF, Huang W, Shellito JE, Mason C, Ramsay AJ (2016) Gene-based neonatal immune priming potentiates a mucosal adenoviral vaccine encoding mycobacterial Ag85B. Vaccine 34:6267-6275

149. Sedegah M, Hoffman SL (2006) Immunological responses of neonates and infants to DNA vaccines. Methods Mol Med 127:239 251 